2. Auf Physiologie und Pathologie bezägliche Methoden. Von

\title{
- F. Hofmeister.
}

\section{Bestimmung des Stickstoffs im Harn mit unterbromigsaurem} Natron. Henninger ${ }^{1}$ ) hat vor Jahren eine Abänderung des Kjeldahl'schen Verfahrens angegeben, bei welcher nach erfolgter Zersetzung mit rauchender Schwefelsäure unter Zusatz von Quecksilber das entstandene Ammoniak mit Bromlauge in Stickstoff übergeführt and als solcher gemessen wird. Vor Zusatz der Hypobromitlösung soll mit Natronlauge bis nahe zur neutralen Reaction versetzt, dann von dem entstandenen Niederschlag abfiltrirt werden. Wie H. Moreigne ${ }^{2}$ ) zeigt, kann jedoch dieser Niederschlag merkliche Mengen Stickstoff (in Form von Tetramercurammoniumsulfat) enthalten. Soll daher die volu-

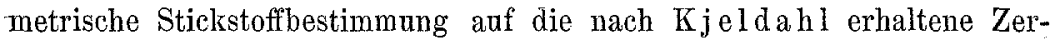
setzungsflüssigkeit Anwendung finden, so muss der Quecksilberzusatz unterbleiben.

M. G. Mereier ${ }^{3}$ ) und G. Cavalle $0^{4}$ ) haben neue Apparate zur Bestimmung des Stickstoffs im Harn mittelst Bromlauge angegeben, auf die hier nur hingewiesen werden kann.

Bestimmung des Harnstoffs. B. Schöndorff ${ }^{5}$ ) hat die von Pflüger und L. Bleibtre $u^{6}$ ) zur Bestimmung des Harnstoffs im Harn angegebene Methode auch für Blut verwendbar gefunden. Bei Untersuchung von Organen lieferte sie jedoch unrichtige und zwar zu hohe Werthe, anscheinend wegen Anwesenheit von stickstofihaltigen durch Phosphorwolframsäure fällbaren Substanzen, die bei dem angewandten Verfahren (Erhitzen mit Phosphorsäure auf $230^{\circ}$ ) Ammoniak abspalten. Schöndorff hat darum eine Anzahl von stickstoffhaltigen Substanzen, deren Vor-

1) Compt. rend. de la soc. de biologie 1884, S. 474. Ganz ähnliche Vorschläge machten später Bayrac (Thèse, Lyon 1887, S. 58), sowie Petit und M onfet (Journ. de Pharm. et de Chim. 1893, S. 297).

2) Bull. de la soc. chim. de Paris [3] 11, 959. Vergl, auch die Reclamation von Bayrac, ebenda S. 1139 .

3) Journ. de Pharm. et de Chim. [6] 2, 11. Auch Chem. Centralblatt 1895, II, S. 410.

4) Deutsche medic. Wochenschrift 21, 548.

5) Archiv f. d. gesammte Physiologie von E. Pflüger 54, 423 und 62, 1.

6) Diese Zeitschrift 28, 379. 